PHYSICAL REVIEW A 93, 049905(E) (2016)

\title{
Publisher's Note: Generic quantum walks with memory on regular graphs \\ [Phys. Rev. A 93, 042323 (2016)]
}

Dan Li, Michael Mc Gettrick, Fei Gao, Jie Xu, and Qiao-Yan Wen

(Received 19 April 2016; published 27 April 2016)

DOI: 10.1103/PhysRevA.93.049905

This paper was published online on 15 April 2016 with an error in the affiliation list. The second affiliation should read as "The De Brún Centre for Computational Algebra, School of Mathematics, The National University of Ireland, Galway, Ireland." The affiliation has been corrected as of 20 April 2016. The affiliation is correct in the printed version of the journal. 